\title{
Márgara Villegas, traductora de John Dos Passos
}

\author{
Rosa María Bautista Cordero ${ }^{1}$
}

Recibido: 30 de noviembre de 2016 / Aceptado: 14 de marzo de 2017

Resumen. Cuando se estudia la relación de John Dos Passos con España, surge invariablemente el nombre del traductor de Manhattan Transfer al español, José Robles Pazos, por su misteriosa muerte en la Guerra Civil española. En esa trágica narrativa, su mujer, Márgara Villegas, ha permanecido hasta ahora en un segundo plano, como víctima colateral. Sin embargo, Márgara fue también traductora de John Dos Passos y de otros autores para Cenit en la España de la República y, posteriormente, continuó traduciendo en el exilio mexicano para el Fondo de Cultura Económica. En este artículo proponemos una semblanza de Márgara Villegas, traductora, una mujer fuerte a pesar de las trágicas circunstancias que convirtieron a su esposo, el traductor de Manhattan Transfer, en uno de los traductores más visibles del polisistema español.

Palabras clave: John Dos Passos, Manhattan Trasnfer, José Robles Pazos, Márgara Villegas, Segunda República.

\section{Márgara Villegas, Translator of John Dos Passos into Spanish}

Abstract. When analyzing the relationship of John Dos Passos and Spain, the name of José Robles, his friend and translator of Manhattan Transfer into Spanish, invariably appears; his misterious killing by the Russians during the Spanish Civil War is central to understand John Dos Passos' relationship with Spain and his political shift. In this narrative, Márgara Villegas, Robles's wife, has always played a secondary role, that of a victim. However, Márgara Villegas also translated John Dos Passos and other writers in the Spain of the Second Republic for Cenit, and later, in exile in Mexico, for the Fondo de Cultura Económica. In this article we will deal with her work as a translator, to provide a fuller picture of a brave, admirable woman, despite the circumnstances that made her husband, the Spanish translator of Manhattan Transfer, tragically visible in the Spanish polysystem.

Keywords: John Dos Passos, Manhattan Transfer, José Robles Pazos, Márgara Villegas, Spain Second Republic

Sumario: 1. Consideraciones preliminaries. 2. Márgara, traductora. 3. Apéndice: Bibliografía de las traducciones publicadas por Márgara Villegas.

Cómo citar: Bautista Cordero, R, M. (2017) Márgara Villegas, traductora de John Dos Passos, en Estudios de Traducción 7, 191-203.

1 Universidad Alfonso X El Sabio

rosa@rosenvinge.org 


\section{Consideraciones Preliminares}

Dentro de los estudios literarios, la literatura traducida ha sido un área de investigación ampliamente ignorada, ya que solemos poner el énfasis en la originalidad y creatividad de la obra literaria y así, un poco entre todos, hemos convertido el texto traducido en una obra secundaria y, a menudo, desdeñada. A esta visión hemos contribuido frecuentemente los propios traductores y traductólogos, dedicando buena parte de nuestra investigación a señalar los errores de traducción, o a analizar los matices que se pierden, desde un punto de vista casi exclusivamente lingüístico. Si bien es cierto que estos análisis nos ayudan a reflexionar sobre cuáles son los enfoques de traducción más adecuados en función de los textos, las épocas, el skopos, etc., pensamos que también es importante destacar el papel fundamental que las traducciones y los traductores desempeñan en nuestro polisistema cultural (Even Zohar 1990).

Como bien observó el traductólogo Lawrence Venuti al referirse a la marginalidad de la actividad traductora, «translation is ignored [...] even by the most sophisticated scholars who must rely on translated texts in their research and teaching» (Scandals 32). Sin embargo, el estudio de la literatura traducida en el contexto de la literatura comparada ofrece muchas e interesantes oportunidades para la investigación. El papel desempeñado por los traductores en cada momento cultural de la historia, así como las circunstancias que influyeron en su trabajo y en su modo de traducir es una de ellas. La mítica invisibilidad de los traductores ha sido combatida en los últimos años por diversos autores como Lawrence Venuti (1985/2008) y Anthony Pym, entre otros, quienes han buscado poner en valor su trabajo, no solo en términos de derechos de autor y reconocimiento social, sino también en un sentido más abstracto (cf. Pym 21-44). Por otro lado, como señalaron los traductólogos pertenecientes al denominado «giro cultural» en los estudios de traducción, cuando nos acercamos a la traducción de los textos literarios se hace particularmente necesario tener en cuenta otros elementos más allá de los puramente lingüísticos, dado que la traducción literaria se caracteriza por ser el resultado de una serie de factores que influyen en la comprensión e interpretación del texto original por parte del traductor - el elevado grado de lenguaje ilocutivo, profusión de elementos culturales foráneos y posible disparidad en la poética de la lengua origen y la lengua meta-, valores sociales, grado de presión que una cultura pueda ejercer sobre la otra, etc. (cf. Berman 1985; Simeoni 1998; Maier 2007). Además, comparto la opinión de Hermans (1985), André Lefevere y Susan Basnett (1990), pertenecientes a la denominada «Escuela de la Manipulación», en cuanto a que para comprender la historia de la literatura traducida hay otros factores de peso que se deben tener en cuenta, tales como el poder, la ideología y el efecto manipulador que estos pueden tener sobre el traductor. A la luz de este marco teórico, dentro de la historiografía y la sociología de la traducción y desde una perspectiva cultural, nos acercaremos en este artículo a Márgara Villegas y a su trabajo como traductora, que se inició en la década de 1920, una época fascinante en España desde el punto de vista sociocultural y editorial. 


\section{Márgara, traductora}

\subsection{Motivación}

Entre 1929 y 1930, José Robles Pazos y su mujer, Márgara Villegas, publicaron por encargo de la editorial comunista madrileña Cenit las dos primeras traducciones de las obras de John Dos Passos al español, Manhattan Transfer y Rocinante vuelve al camino, respectivamente. Ambas continúan publicándose. El título de este artículo no es casual. «Márgara, traductora de John Dos Passos» busca poner en plano de igualdad el trabajo de esta traductora y el de su marido, José Robles, que ha pasado a la historia como «el traductor de John Dos Passos», pero que, al igual que Márgara, tan solo tradujo una de sus obras; ambos, además, mantuvieron una amistad entrañable con el escritor norteamericano que perduró más allá de la muerte de «Pepe», con correspondencia frecuente e incluso una visita de Dos Passos a Márgara en los años 60 en México, acompañado de su segunda esposa y su hija Lucy (Dos Passos, L.). No pretendemos en este trabajo ahondar en los aspectos biográficos que hicieron tristemente conocido a José Robles y que han sido ya tratados en profundidad por otros autores en diversas ocasiones, entre ellos el extraordinario trabajo de Martínez de Pisón en Enterrar a los muertos (2005). El asesinato y posterior desaparición de Robles en Valencia en 1937, con casi toda certeza a manos de los rusos, ha contribuido significativamente a mantener el nombre de John Dos Passos muy presente en la crítica literaria española hasta nuestros días, como parte del boom crítico-literario en torno a nuestra guerra civil. La historia de su amistad, tantas veces contada, fue nuevamente abordada en 2015 en el riguroso documental Robles, duelo al sol, de Sonia Tercero. En publicaciones anteriores (Bautista 2011; 2013), abordamos las traducciones de Manhattan Transfer como parte de un estudio más amplio relacionado con la presencia de John Dos Passos en el polisistema espa$\tilde{n}^{2}{ }^{2}$. En el trascurso de nuestra investigación sobre John Dos Passos en España, hemos podido constatar que buena parte de las reescrituras asociadas a este autor tienen que ver de forma directa con el traductor de Manhattan Transfer, José Robles. En cambio, la figura de Márgara Villegas, traductora de Rocinante vuelve al camino e íntimamente asociada a ambos, solo aparece en un segundo plano, como esposa y madre desesperada por encontrar respuestas a la desaparición de su marido durante la guerra civil. En aquellos días terribles en Valencia, en los que Pepe Robles fue detenido, el escritor Francisco Ayala recuerdaa a Márgara «de un sitio para otro, preguntando, averiguando, inquiriendo siempre sin el menor resultado» (Ayala, Recuerdos y Olvidos 229-30). Sin embargo, además de esposa y madre en circunstancias muy adversas, Márgara fue traductora profesional hasta al menos 1966, última fecha de la que tenemos constancia de una traducción suya publicada en México. Con estas páginas queremos recordar esa parte de su historia personal y dar visibilidad a su trabajo como traductora.

2 Bautista Cordero, Rosa María. "The Spanish Translations of Manhattan Transfer and Their Role in the Spanish Construction of John Dos Passos”. Tesis doctoral inédita. Universidad Autónoma de Madrid 2016. 


\subsection{Semblanza biográfica}

Margarita Fernández de Villegas, que firmó sus traducciones como Márgara Villegas y, posteriormente, como Margarita Villegas de Robles, nació en Madrid a finales del siglo XIX y falleció en México, en el exilio, en 1983 (cf. Martínez de Pisón 199). Márgara nació en el seno de una familia bohemia y liberal, la tercera de cuatro hermanas. Su padre, Francisco Fernández Villegas, conocido por su pseudónimo «Zeda» (1856-1916), fue pedagogo, periodista, crítico teatral y escritor. La hermana mayor de Márgara era la actriz Amparo Fernández Villegas, muy conocida en los teatros españoles de antes de la guerra, y posteriormente célebre en México sobre todo por su papel de Celestina, además de por sus numerosísimas actuaciones en papeles secundarios de teatro y telenovelas. Márgara, al igual que sus tres hermanas, estudió en la Institución Libre de Enseñanza, donde recibió una educación vanguardista. Posteriormente estudió Escultura en la Academia de Bellas Artes de San Fernando, aunque jamás se dedicó a las artes plásticas. Su verdadera afición eran los libros y el teatro.

Márgara Villegas fue una de aquellas mujeres que en la década de 1920 representaban la élite cultural e intelectual madrileña, adelantadas a su tiempo, entre las que destacaron entre otras Maruja Mallo, Concha Méndez, Rosa Chacel o María Zambrano, por citar a algunas. Conoció a José Robles Pazos, el amor de su vida, cuando era estudiante de Escultura en la Escuela de Bellas Artes de San Fernando, aunque dicen que ella hubiese preferido estudiar Filosofía y Letras. Era muy aficionada a la lectura, las tertulias y el teatro, donde solía acudir a menudo gracias a las invitaciones que les proporcionaba su hermana Amparo, que como mencionamos anteriormente era una renombrada actriz de la época. En esos años de juventud Márgara y Pepe Robles conocieron a John Dos Passos, aún muy joven y comenzando a escribir, y a Maurice Coindreau, el célebre traductor francés que también lo fue de John Dos Passos, y que en esa época estudiaba en la Universidad de Madrid. Márgara — que se había quedado huérfana en 1916 - se casó con Pepe Robles en 1919 y, muy pronto, tuvo a su primer hijo, Francisco "Coco" Robles; Coindreau fue su padrino. Dicen que el hecho de que Márgara perteneciese a una familia bohemia había distanciado a Márgara y Pepe de la familia de este, tradicional y conservadora, lo que quizás fue uno de los motivos que empujó a Pepe a buscar oportunidades en EE.UU. En 1920, Pepe consiguió una plaza de profesor de español en la Universidad Johns Hopkins de Baltimore y, al poco tiempo, nació allí la segunda hija del matrimonio, Miggie. En aquellos primeros tiempos en EE.UU. pasaron algunas estrecheces económicas (Dos Passos tuvo que prestarles dinero para operar a Coco de apendicitis), mientras Pepe se volcaba en consolidar su puesto de profesor en la universidad. (cf. Martínez de Pisón 9-50)

Durante los veranos solían volver a Madrid, donde se alojaban normalmente en algún piso que les cedían amigos o conocidos durante sus descansos estivales, y era entonces cuando frecuentaban las tertulias literarias, especialmente la de La Granja El Henar en la Calle Alcalá, en las que Márgara, según cuenta su familia, era una de las poquísimas mujeres toleradas (Ortiz). Según sus allegados, Márgara era una mujer de fuertes convicciones de izquierdas, ávida lectora, de carácter muy alegre y siempre ocurrente y bromista, con una gran facilidad para jugar con las palabras. Cuentan también que, cuando estaba enfrascada en la lectura, se le pasaban las horas sin darse cuenta, y se olvidaba de las rutinas caseras y de los niños (Azcárate). La 
pasión por los libros la acompañó hasta el final de sus días, rodeada de papeles, diccionarios desgastados por el uso y, en su mesita, siempre un libro, según recuerda su nieto Mauricio. Al intentar recordar cuáles eran las lecturas favoritas de Márgara, afirma: «Siempre hablaba de libros, de autores y de anécdotas del mundo literario [...] Valle, desde luego, y Galdós y Azorín, pero también los rusos y ahora mismo me viene a la cabeza una lectura favorita: Jules Romains y los veintisiete tomos de Los hombres de buena voluntad». Admiraba a Quevedo y Calderón, y sentía adoración por Lope de Vega. García Lorca, Machado y Cernuda eran sus preferidos de la generación del 27. En su círculo de amistades había escritores como Valle-Inclán y León Felipe, su amigo fiel en el exilio; otros, como Rafael Alberti o Wenceslao Roces fueron compañeros de tertulia hasta que los acontecimientos de la guerra hicieron que la familia Robles se enemistara para siempre con ellos: Márgara sintió su amistad traicionada por la inacción de ambos ante la detención y posterior ejecución de su marido.

\subsection{Los años como traductora de la editorial Cenit}

En 1930, Márgara Villegas publicó por encargo de la editorial madrileña Cenit la traducción de la segunda obra de John Dos Passos al español, Rocinante vuelve al camino. La primera, Manhattan Transfer, había sido publicada también por Cenit el año anterior, aunque en aquella ocasión la traducción era de su marido, José Robles Pazos, quien en esas fechas también había firmado la traducción de Babbit, novela del premio Nobel de Literatura estadounidense Sinclair Lewis. En el caso de las dos traducciones de las obras de John Dos Passos, ambas continúan publicándose atribuidas a José Robles y Márgara Villegas, respectivamente. La editorial encargó la traducción de otros tres libros a Márgara: Judios sin dinero (1930), de Mighael Gold, El pecado rojo (1931), de Julia Peterkin, y La compañía. (1932), de Edwin Seaver. La primera de ellas, Judios sin dinero, fue un gran éxito en EE.UU. en los años 30 del siglo Xx. Se trata de una novela proletaria que habla de las penurias de los inmigrantes judíos en el Lower East Side neoyorquino de principios de siglo. Curiosamente, la traducción de Márgara Villegas ha sido recuperada para su reedición en 2015 por la editorial Dirección Única Ediciones. He aquí un fragmento que nos recuerda mucho a las descripciones del Nueva York de Manhattan Transfer:

Carros y carros pasaban traqueteando. Un calderero remendón martilleaba el cobre. Las campanillas de los traperos repiqueteaban. Torbellinos de polvo y de periódicos. Las prostitutas reían a carcajadas. Pasaba un profeta, un trapero judío de barba blanca. Los granujas bailaban alrededor del organillo. Dos vagos se golpeaban. ¡Bullicio, suciedad, riñas, caos! El estruendo de mi calle se alzaba como la explosión de un carnaval o de una catástrofe. El ruido resonaba continuamente en mis oídos. Hasta dormido lo oía. Lo oigo ahora. (10)

La segunda de ellas, El pecado rojo (en inglés titulada Scarlet Sister Mary) fue escrita por la novelista estadounidense Julia Mood Peterkin, quien ganó el premio Pullitzer por esta historia en 1929. Trata de la vida de una joven huérfana en Carolina del Sur, Mary, que se debate entre su deseo de mantener una buena reputación conforme a la doctrina de la iglesia, y la tentación de vivir los placeres terrenales. Tachada de obscena, fue prohibida en algunos lugares de EE.UU. por escandalosa. 
Finalmente, la última de ellas, La Compañía, trata de las vidas que se entrecruzan en la oficina, desde una perspectiva existencialista en la que los personajes van desvelando poco a poco la crudeza de su verdadera existencia más allá de las apariencias. Su autor, simpatizante comunista, colaboró en publicaciones izquierdistas nosteamercianas como The New Masses o The Partisan Review.

La editorial Cenit pertenecía a un grupo de pequeñas editoriales conocidas como Editoriales de avanzada, que se crearon en España en el periodo comprendido entre 1927 y 1933 como resultado de los nuevos movimientos obreros que surgieron por toda Europa, y como reacción a los horrores de la Primera Guerra Mundial. En las primeras décadas del siglo Xx, España continuaba inmersa en una enorme inestabilidad política, entre la agónica monarquía de Alfonso XII y la dictadura de Primo de Rivera (que finalizó en 1931 con la proclamación de la Segunda República). Los nuevos movimientos politicos internacionales, principalmente el socialismo y el fascismo, también llegaron España y el ambiente soiopolítico quedó reflejado en las tendencias editoriales de la época (Santonja). Así, surgieron una serie de editoriales nuevas que se centraron en la publicación de libros socio-revolucionarios, tanto de ficción como divulgativos.

En los últimos tiempos de la monarquía, el libro social de tendencia revolucionaria invade el mercado editorial. Con agudo sentido comercial, los editores, viendo la dirección en la que se movía el público, se dedicaron a lanzar libros que [...] significaban repudio del régimen político-social establecido. Estos libros, de gran éxito editorial, contribuyeron a la formación de una nueva conciencia políticosocial revolucionaria en las capas medias de la sociedad española. (V. Fuentes 545)

Estos empresarios editoriales, en su mayoría jóvenes comunistas que solían escribir para la revista Post-Guerra y que se reunían em la tertulia del Café Savoia de Madrid (V. Fuentes 545), lograron burlar la censura de Primo de Rivera y publicar libros "revolucionarios". La estrategia era sencilla; aparentemente, las autoridades estaban preocupadas por la propagación de ideas subversivas entre la clase obrera y ejercían una fuerte censura sobre los panfletos y la prensa, pero no se preocuparon de regular la censura de libros al pensar que la clase obrera, pobre e inculta, no tendría acceso a ellos. En palabras de Gonzalo Santonja:

(...) preocupado por la honda penetración de 'ideas peligrosas' en los ambientes populares a través de periódicos, revistas [...] Primo de Rivera se apresuró a imponer un rígido sistema de censura previa a las publicaciones periódicas haciendo caso omiso de todos aquellos libros que alcanzasen un mínimo de doscientas páginas. (La República de los libros 10).

Estando así las cosas, los fundadores de Post-Guerra decidieron renunciar a la publicación de su revista y crearon Ediciones Oriente, una editorial que les permitiría hacer oposición al Gobierno a través de la publicación de libros radicales de más de 200 páginas. El nombre elegido era en sí mismo toda una declaración de intenciones: un modo de marcar la diferencia con la prestigiosoa Revista de Occidente. dirigida por Ortega y Gasset (V. Fuentes 546). La intención del consejo editorial era inicialmente más ideologica que lucrativa, y como recuerda uno de sus fundadores, 
José Venegas, en su libro Andanzas y recuerdos de España, nunca esperaron tener éxito comercial, sino difundir la obra de autores radicales extranjeros. Si embargo, y contra lo esperado, Ediciones Oriente tuvo un enorme éxito commercial, y algunos de sus miembros la abandonaron para inicar su andadura de forma independiente. Así fue como Rafael Giménez Siles y Juan Andrade Rodríguez crearon la editorial Cenit (1928-1936), junto al abogado republicano radical Graco Marsá. Giménez Siles había conocido a Juan Andrade en la Cárcel Modelo de Madrid, donde habían sido internados por su oposición política al Gobierno. En palabras de Santonja:

Y en la mismísima cárcel Modelo, considerando la favorable acogida de los lectores, pero advirtiendo asimismo la inadecuada estructura comercial e interna de Ediciones Oriente, Giménez Siles y Graco Marsá, obteniendo además la valiosa incorporación de Juan Andrade (muy bien introducido en los sugerentes ambientes de la joven intelectualidad revolucionaria europea), acordaron crear una nueva editorial. ("Breve Perfil" 129)

Entre 1931 y 1936, Wenceslao Roces, comunista y profesor de Derecho en la Universidad de Salamanca, se convirtió en el director de Cenit. A lo largo de su existencia, publicaron más de 200 títulos en 25 colecciones de diversos géneros, desde ensayos políticos a teatro y novela, pasando por manuales de salud e higiene. (Santonja, "Breve perfil de la editorial Cenit" 132-3).

Si bien un puñado de los autores publicados por Cenit eran estadounidenses, como John Dos Passos o Sinclair Lewis, muchos de ellos procedían de la Unión Soviética y Alemania (ibid 138). La larga lista incluía a Henri Barbusse, Herman Hesse, Upton Sinclair, Mijail Cholokhov, Fedor Gladkov, Karl Marx, Fiedrich Engels y Máximo Gorki, entre otros. El número de autores extranjeros superó a los españoles, entre los que estaban Ramón J. Sender y César Vallejo. La intensa actividad editorial de Cenit generó, a su vez, una ferviente actividad traductora de la que Márgara formó parte junto a un nutrido grupo de colegas entre los que se encontraban, entre otros, Andreu Nin, Wenceslao Roces y José María Quiroga Plá, además del poeta César Vallejo. Dado que los archivos de Cenit no se han conser-

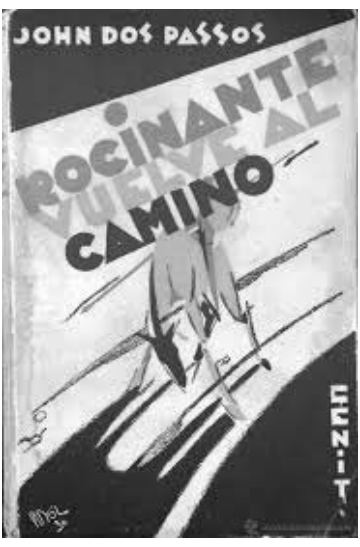
vado, o al menos no hay conocimiento de cuál fue su destino ${ }^{3}$, disponemos de escasos datos de todos los traductores que colaboraron con ellos, pero de la información disponible se desprende que había una minoría femenina representada por la propia Márgara Villegas y por otra traductora de gran actividad en esos años, Piedad de Salas de Lifchuz, que traducía del ruso. Dado que el francés era la lengua más estudiada en aquellos años en España, no era raro que se tradujeran obras rusas, alemanas o americanas desde el francés. En el caso de Márgara, aprendió francés en la Institución Libre de Enseñanza, pero no sabemos a ciencia cierta cómo aprendió inglés,

3 El bibliófilo Abelardo Linares opina que es posible que se destruyeran todos los papeles al estallar la Guerra, o que el propio Roces los llevara consigo a su exilio en México. 
ya que la Institución lo introdujo años más tarde como materia obligatoria. Hay anécdotas familiares que recuerdan que no le gustaba demasiado hablarlo, a pesar de haber vivido en los EE.UU. durante más de 15 años.

Desde nuestra perspectiva actual, podemos afirmar que Cenit y las otras editoriales de avanzada desempeñaron un papel crucial. Ampliaron nuestro sistema cultural no solo por abrirlo a las visiones más avanzadas y radicales de su época, sino porque lo hicieron para un público mucho más amplio que hasta entonces. A ello contribuyeron, sin duda, la difusión de muchos de sus títulos en las Bibliotecas Circulantes Populares de la Segunda República, que fueron en su mayoría expoliadas tras estallar la guerra civil. Santonja resume así el importante papel de difusión cultural que tuvo la editorial:

En definitiva, los hombres de Cenit —encabezados por Giménez Siles - cumplieron una función de singular trascendencia $[\ldots]$ en la incorporación a nuestro panorama cultural de una crecida nómina de autores europeos y norteamericanos que por derecho propio figuran en la historia de la literatura contemporánea (recordaré algunos nombres: Herman Hesse, Dos Passos, Sinclair Lewis, [...] en la divulgación rigurosa de postulados marxistas $[\ldots]$ y en el acierto $[\ldots]$ al facilitar cauce de expresión a dos jóvenes autores de considerable proyección: César Vallejo y Ramón J. Sender. (La República de los libros 76)

\subsubsection{Rocinante vuelve al camino}

La traducción de Rocinante vuelve al camino pertenece a lo que Santonja considera el periodo inicial de Cenit (1928-1932), en el que se publicaron sobre todo obras literarias de ficción, en su mayoría novelas. Sus autores eran lo que la editorial denominaba novelistas nuevos, escritores cuyas obras tenían un fuerte componente político o social y, en muchos casos, también una actitud de rechazo y protesta frente a la guerra. Quizás fue esto lo que llevó a Giménez Siles a publicar las traducciones de dos obras de Dos Passos, cuya reputación como activista social y simpatizante de la izquierda estaba intacta en aquellos años, reforzada por su denuncia de los horrores de la guerra en su novela Three Soldiers $(1921)^{4}$.

La obra original, Rosinante to the Road Again, fue publicada por Dos Passos en 1922, y reúne una recopilación de los principales escritos de Dos Passos sobre España hasta esa fecha. Su contenido es muy interesante, pues recoge las impresiones del escritor sobre nuestro país y da cuenta de su profundo conocimiento de nuestros escritores y de nuestra historia, aunque es algo incoherente en su estructura, que alterna escritos de Dos Passos sobre distintos aspectos de la literatura, la historia y la cultura españolas, con episodios de un viaje de tres días y tres noches con dos personajes ficticios, Telémaco y Lieo, que parten de Madrid hacia Toledo en busca del "gesto" de España, de la esencia de lo español. En su traducción, Márgara muestra un hábil manejo del español, transmitiendo una gran expresividad y fuerza, respetando el original con gran naturalidad y, en general, trasladando ingeniosamente sus

4 The Spanish translation of Three Soldiers (Tres Soldados) was published in 1948 by José Janés, Barcelona firmada por Mary Rowe. The currently available edition (Debolsillo 2014) is credited to the same translator. 
matices y colores. A continuación repasaremos brevemente algunas de las estrategias de traducción que, a nuestro parecer, caracterizan el enfoque traductor de Márgara en Rocinante vuelve al camino.

El primer aspecto que llamó nuestra atención fue cómo Márgara en ocasiones omite en la traducción algunas cosas que debía considerar innecesarias para el lector meta español. Así, al comienzo de la obra, que arranca en una cervecería de la madrileña Plaza de Santa Ana, "El oro del Rhin", Márgara optó por eliminar el dato de la ubicación, quizás motivada por el hecho de que en 1930 la cervecería era de todos conocida. De manera que cuando Dos Passos dice "in the cafe Oro del Rhin, Plaza Santa Ana, Madrid", Márgara tradujo "en El Oro del Rhin", sin mencionar el tipo de establecimieno, ni la ubicación.

Desde el punto de vista del ritmo de la prosa y del efonque narativo característicos de Dos Passos, observamos en las estrategias de traducción de Márgara cierta tendencia a a la desviación con respecto del original, relacionada con alteraciones sintácticas y de puntuación, un mecanismo frecuente en la traducción de prosa que el francés Antoine Berman denominaba "racionalización". Pongamos un ejemplo:

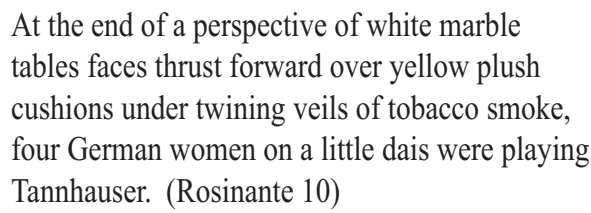

Sobre una pequeña tarima situada al extremo de una fila de blancas mesas, cuatro alemanas tocaban Tannhauser. Los parroquianos alargaban la cabeza entre espirales de humo de tabaco.

(Rocinante 13-14)

En este ejemplo la versión española, además de cambiar la perspectiva de la escena, omite los cojines amarillos que ya han aparecido en la página anterior y que son un elemento de conexión entre las distintas imágenes que se suceden dentro del café, en un incipiente ensayo de la técnica del camera eye característica de las novelas modernistas de Dos Passos, en la que utiliza imágenes cinematográficas en sus descripciones, y que lamentablemente no se ha reproducido en la traducción.

Hay, en cambio, otros momentos en los que Márgara muestra una gran habilidad y respeto por los rasgos de la prosa original al trasladarla al español. Pongamos de ejemplo la escena que dedica Dos Passos a Jorge Manrique, en la que a nuestro juicio la descripción de Dos Passos está acertadamente vertida al español:

They thought of him in the court of his great dustcoloured mansion at Ocaña, where the broad eaves were full of a cooing of pigeons and the wide halls had dark rafters, painted with arasbesques in vermilion, in a suit of black velvet, writing at a table under a lemon tree. (11)
Se lo figuraban en el patio de su polvorienta mansión de Ocaña, cuyos anchos aleros estaban llenos de arrullos y cuyos amplios corredores tenían oscuras vigas con arabescos pintados de bermellón, vestido de terciopelo negro, escribiendo en una mesa bajo un limonero. (15)

Uno de los rasgos más característicos del modo de traducir de Villegas es la habilidad con la que consigue que la voz narrativa se exprese con gracia y naturalidad. 
Como ejemplo, podemos tomar un fragmento de la parte tercera del capítulo III, «El panadero de Almorox»:

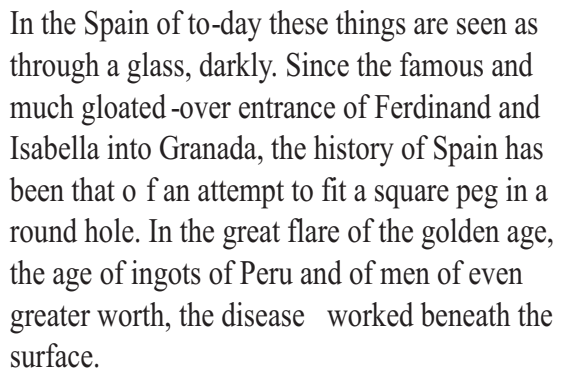

En la España de hoy, estas cosas se ven como a través de un c ristal: borrosamente. Desde la famosa entrada de Fernando e Isabel en Granada, tan cacareada, la historia de España ha sido un continuo esfuerzo para encajar un taco cuadrado en un agujero redondo. En la gran llamarada del siglo de oro, el siglo de los lingotes del Perú y de los hombres de mayor valor todavía, el mal fermentaba bajo la superficie.

Finalmente, hemos detectado que hay algunas omisiones en el texto de Villegas que quizás se deban a falta de revisión, bien a una cuestión de autocensura. Nos referimos, por ejemplo, a una conversación de Dos Passos con un soldado artillero en Segovia, a quien pregunta las señas para ir a casa de Antonio Machado (147). La frase omitida es "I'd give it all for a puff of gasoline from a Hispano-Suizo.... D'you know the Hispano-Suizo?" No sabemos qué pudo provocar esta omisión, tan solo podríamos hacer alguna conjetura al respecto. Quizás la referencia al anhelo del soldado por un coche de lujo podría haber resultadoinadecuada para los lectores comunistas de Cenit y, por lo tanto, eliminada. En su conjunto, salvando las omisiones injustificadas y la racionalización de algunos fragmentos, la traducción de Rocinante vuelve al camino está llena de méritos y prueba de ello es que sigue vigente en la actualidad.

\subsection{Los años del Fondo de Cultura Económica en México}

Aunque Márgara tradujo otras tres obras para Cenit desde su casa de Baltimore después de Rocinante vuelve al camino, a partir de 1931 la editorial comenzó a tener problemas de distribución con la quiebra de la Compañía Iberoamericana de Publicaciones (CIAP), y fue decreciendo en actividad hasta su cese en la guerra civil, y no volvemos a encontrar rastros de la actividad traductora de Márgara hasta los primeros y difíciles años de su exilio en México en los años 40. En efecto, después de su decisión de quedarse en España al servicio de la República el fatídico verano de 1936, la vida acomodada de la familia Robles se transformó en una pesadilla tras la detención y posterior fusilamiento del padre. Tras muchos meses de angustia hasta tener la certeza definitiva de la muerte de su marido, ejecutado por sospecha de espionaje por los rusos, Márgara tuvo que enfrentarse primero al rechazo público de algunos antiguos conocidos (Roces, Alberti, Hemingway), y después a una difícil época en la que, además de la gran depresión por lo sucedido a su marido, tuvo que sufrir el encarcelamiento y condena a muerte (luego conmutada) de su hijo Coco. Huyó con su hija Miggie y su hermana Concha a Paris al final de la guerra tras un paso breve por Barcelona y, finalmente, se instaló en México tras una corta estancia en Baltimore, donde pudo solucionar los asuntos del seguro de vida de Pepe que 
logró cobrar gracias a la intermediación de John Dos Passos (Tercero). Las cartas de Márgara a Dos Passos en esos años, siempre escritas en español, denotan la angustia de su situación y, a la vez la entrañable amistad que les unía. Su correspondencia se prolongó hasta los años 60.

En aquellos años de estrecheces económicas, para Márgara la traducción supuso un medio de salir adelante, como para tantos otros españoles que habían buscado en México una nueva vida. Aquella actividad traductora en el exilio fue posible gracias a que algunos intelectuales españoles iniciaron empresas editoriales que, sobre todo en los primeros tiempos, supusieron una oportunidad de trabajo para los que hablaban idiomas, aunque hubiesen tenido otras ocupaciones antes de la guerra, y también, por supuesto, para escritores y traductores exiliados. Entre ellos se encontraba Margarita Villegas de Robles, nombre con el que Márgara, ya viuda, firmó sus traducciones a partir de ese momento. En su época mexicana, Márgara publicó nueve traducciones del ámbito de las ciencias sociales para la editorial Fondo de Cultura Económica, con Alfonso Reyes al frente, quien apreció mucho su trabajo (Ortiz); posiblemente colaboró también con la editorial UTEHA dirigida por el catedrático Recasens Sitges, y quizás para la editorial Séneca del poeta José Bergamín. (Azcárate). Lamentablemente no hemos podido corroborar estos datos, basados en testimonios de sus allegados. En México, Márgara prosiguió su amistad con León Felipe y fue gran amiga de la familia Marichal, también exiliados españoles, en especial de Carlos, el pintor, de quien tenía un cuadro muy bonito de una calle en Ciudad de México que adornó su cuarto hasta el fin de sus días (Ortiz). Jamás volvió a casarse y, según cuenta uno de sus nietos, Mauricio Ortiz, a pesar de recordarla siempre como una mujer alegre y vivaracha, nunca dejó de lamentar la pérdida del abuelo, con quien tanto había compartido y a quien perdió siendo aún tan joven.

Las últimas traducciones publicadas de Margarita Villegas de Robles de las que tenemos constancia son Introducción a la Arqueología de Creta, de Pendlebury, publicada en 1965, y Ur, la ciudad de los Caldeos, publicada en 1966. Algunas de sus traducciones de la etapa mexicana, como La nueva Atlántida, de Francis Bacon, y Autoridad e Individuo, de Bertrand Russell, se reeditan de cuando en cuando, al igual que Rocinante vuelve al camino, que sigue vendiéndose en las librerías españolas. Sirvan estas líneas para completar el retrato de esta mujer, fuerte a pesar de las dificultades y una de las pioneras de la traducción profesional.

\section{Apéndice: Bibliografía de traducciones publicadas por Márgara Villegas.}

A continuación incluimos los títulos que hemos logrado recopilar de las traducciones que publicó Márgara Villegas a lo largo de su vida. Para elaborarla, hemos consultado los datos disponibles de la editorial Cenit y del FCE, junto con referencias bibliográficas incluidas en artículos sobre diversos temas relacionados con la época de la publicación de las obras, así como a su nieto, Mauricio Ortiz. Posiblemente esté aún incompleta, teniendo en cuenta que quizás tradujera otros textos en los que no constara su nombre. Hay aquí, en total, trece títulos: cuatro realizados desde EE.UU. para la editorial Cenit y, los restantes, desde el exilio en México, para el Fondo de Cultura Económica (FCE). 
Bacon, F. "La nueva Atlántida” en Imaz E. (ed). Utopías del Renacimiento. México: FCE, 1941. (253-303).

Barrow, R.H. Los romanos. México: FCE, 1950.

Brailsford, H. N. Shelley, Godwin y su círculo. México: FCE, 1942.

Cottrell, L. El toro de Minos. México: FCE, 1958.

Dos Passos, J. Rocinante vuelve al camino. Madrid: Cenit, 1930.

Fishek, A.G. B. Progreso económico y seguridad social. México: FCE, 1949

Gold, M. Judios sin dinero. Madrid: Cenit, 1930.

Gibb, H.A.R. El mahometismo. México: FCE, 1952

Peterkin, J. El pecado rojo. Madrid: Cenit, 1931.

Pendlebury, J.D.S. Introducción a la Arqueología: Creta. México: FCE, 1965.

Rusell, B. Autoridad e individuo. México: FCE, 1949.

Seaver, E. La compañía. Madrid: Cenit 1932.

Wooley, WOOLEY, L. Ur, la ciudad de los caldeos. México: FCE, 1966.

\section{Referencias bibliográficas}

Ayala, F. Recuerdos y Olvidos: 1. Del paraíso al destierro. Madrid: Alianza Editorial 1984.

Baggio, H. Rocinante pierde el camino. Madrid: Altalena 1978.

Bassnett, S. «Introduction». Bassnett, Susan. Translation. London \& New York: Routledge 2014. 1-15.

Berman, A. La traducción y la letra o el albergue de lo lejano. Trad. Ignacio Rodríguez. Buenos Aires: Dedalus 2014.

Broncano Rodríguez, M. «José Robles Pazos: primer traductor de Dos Passos y Lewis». Livius (1992): 233-242.

De Azcárate, L. Entrevista con Rosa María Bautista Cordero. 8 de julio 2015.

Dos Passos, J. Rocinante vuelve al camino. Madrid: Cenit 1930.

—. Rosinante to the Road Again. New York: George H. Doran 1922.

Elorza, A. «La España de John Dos Passos». El País 6 de agosto 2005.

Even- Zohar, I. «The position of translated literature within the literary polysystem». Venuti, Lawrence. The Translation Studies Reader 2nd edition. London and New York: Routledge 2004. 199-204.

Hermans, T. The Manipulation of Literature: Studies in Literary Translation. Beckenham: Croom Hem 1985.

Lefevere, A. Translation, Rewriting and the Manipulation of Literary Fame. London-New York: Routledge 1992.

Linares, A. Sobre Cenit y el tiempo de traducción de las novelas en las editoriales de avanzada. Conversaciones con Rosa María Bautista Cordero. 17 de junio de 2015.

Ludington, T. (ed). The Fourteenth Chronicle. Boston: Gambit 1973.

Ludington, T. «John Dos Passos 1896-1970: Modernist Recorder of the American Scene». Virginia Quarterly Review (1996): 565-580.

Martínez de Pisón, I. Enterrar a los muertos. Barcelona: Seix Barral 2005.

Montes, C. La visión de España en la obra de John Dos Passos. Salamanca: Almar 1980.

Preston, P. El holocausto español: Odio y exterminio en la Guerra Civil y después. Barcelona: Debolsillo 2013. 
-. We Saw Spain Die: Foreign Correspondents in the Spanish Civil War. London: Constable 2009.

Pym, A. Exploring Translation Theories. 2nd edition. London and New York: Routledge 2014.

Pym, A. «The Translator as Non Author and I am Sorry About That». Buffagni, Claudia, Garzelli, Beatrice \& Zannotti, Serenella. The Translator As Author. Berlin: LitVerlag 2011. 31-44.

Robles, Duelo al Sol. Dir. Sonia Tercero. Perf. Lucy Dos Passos. 2015.

Robles, Duelo al Sol. Dir. Sonia Tercero. 2015.

Santonja, G. «Breve perfil de la editorial Cenit». Anuario de la Sociedad Española de Literatura General y Comparada Vol. V (1983-1984): 129-139.

-. La República de los libros: El nuevo libro popular de la II República. Ed. Luis Alberto de Cuenca. Vol. 29. Barcelona: Anthropos 1989.

Venuti, L. The Scandals of Translation: Towards an Ethics of Difference. London and New York: Routledge 1998b.

-. The Translator's Invisibility: A History of Translation. London and New York: Routledge 1995/2008. 